\title{
The Impact of Covid-19 on U.S. Car Industry Based on Fama-French Five Factor Model
}

\author{
$\mathrm{Li} \mathrm{Bai}{ }^{1, *}$ \\ ${ }^{1}$ College of Liberal Arts, Colorado State University, Fort Collins, Colorado 80524, United States \\ *Corresponding author. Email:bailiii@ rams.colostate.edu
}

\begin{abstract}
Asset pricing model reveals the relationship between expected return and risk associated of the portfolios for investors during the investment decision-making process. Concepts (e.g., the correlation of different variables and the growth or decline of the portfolio) are quantified in different models with different expressions. Fama-French five-factor model, as one of the most well-known asset pricing models, has been justified as efficient as reliable in terms of analyzing various portfolios of different market. Starting from the beginning of 2020, the spread of Covid-19 has affected our daily life in many aspects including the stock market. Fama-French five-factor model was adopted to analyze the car industry, and this paper investigates the average value weighted return on portfolios before and during the pandemic to evaluate whether the correlation and the statistical significance of variables is changed. According to the results, investors will be better informed the stability during the pandemic in terms of industries, companies and portfolios. These results shed light for those would like to learn how the pandemic would impact the stock of different industries in the U.S.
\end{abstract}

Keywords: Fama-French model, Covid-19, Car industry, U.S. stock market

\section{INTRODUCTION}

As investors, it is critical for both cooperation and individuals to figure out what the risk they might experience and the return they would receive as compensation. As one of the most direct, straightforward and common quantitative way to express the correlation between return and risk and other factors, asset pricing models definitely are super useful and handy tools in terms of assessing, analyzing and predicting how a portfolio or single stock tend to perform and whether it is sensitive the market changes. In fact, it is the determining factor of every investment decision making and would directly impact investors' behavior. Therefore, determining the validity and accuracy of an asset pricing model is the premise of making right investment decisions, especially under the impact of COVID-19, which left the global economy such a changeable and varied market. During the pandemic, the global economy has been influenced greatly and mostly in a negative manner. Unemployment ratio has risen sharply in many countries and consumption expenditures has dropped greatly as well. Many sectors (e.g., tourism and the aviation industries) are affected negatively. As a consequence, their stock price experienced large decline. In order to make reasonable investment decisions, the best way is effectively evaluating the return and risk. In addition, given that the global market is dramatically fluctuations and unpredictable, the sensitivity of investment portfolios to the market also becomes crucial. A lot of factors would affect the validity and effectiveness of asset pricing. In order to make the most proper decision economically, it is important to use the appropriate model during the decision-making process. COVID-19 has been giving the global economy negative longlasting impacts, correct investment established on the basis of proper asset pricing, could be a rescue to individual investors as well as firms or even the whole industry.

\subsection{Related Work}

The effectiveness of the model has been approved via different studies

\subsubsection{The application of Fama-French model}

According to the study conducted by Chiah et al, compared to other asset pricing models including the 
Fama-French three factor model, the five-factor model did give a superior performance [1]. In order to investigate and compare the ability of different asset pricing models in terms of explaining anomalies, they selected data of 25 size and book-to-market portfolios. By running regressions respectively under three factor model and five factor model, they conclude that the five-factor model does better at capturing the tendency of profitability and investment in stock returns [1].

The model have been applied to different markets in the world. Huang makes research on whether FamaFrench five-factor model performs better while assessing individual stock returns in the Chinese stock market from 1994 to 2016. By summarizing and comparing the summary statistics during the period of 1994-2016 and correlation matrix among the factors of the model, Fama-French five-factor model does deliver a better performance [2].

In addition to being used to assess individual stock returns in Chinese market, the model is also effective when analyzing anomalies. In the study by Lin, the author uses the five-factor model to examine whether the model can be applied to Chinese stock market. In order to assess its validity, Lin established the sample by using data of all firms listed in A-share markets from the China Stock Market \& Accounting Research (CSMAR) Database ranging from the time period between 1996 and 2015 [3]. By testing the statistical summary and correlations under different models with different factors being involved, Lin suggests that the five-factor model constantly outperformances the threefactor model when being used as a reference to analyze the anomalies within the Chinese stock market [3].

The feasibility of the model is also proved in German stock market. Dirkx and Peter implement the Fama-French five factor model to German stock market to confirm its availability [4]. For their study, they extracted data from the Bloomberg database, which covers a time period of 15 years from June 2002 to June 2017 and they chose monthly returns of the CDAX companies as their references [4]. Based on regressions and comparing the coefficient of each components of the five-factor model, the profitability factor is negatively correlated with the size factor while the investment factor is positively correlated to the size and value factor. These conclusions suggest that the new model tends to give more precise prediction compared to the old three-factor model.

Evidence can also be found in American market. Hou and Chen examine and analyze how the pandemic impacted American steel industry by using the FamaFrench five factor model [5]. In order to determine the factors are changed or maintained, they used daily data from Fama-French five-factor model of 30 steel industry portfolios, which consists of earnings, industry size, profit and investment style. According to their results, it is obvious that the pandemic left some significant impacts on the steel industry, which leads the industry to be less sensitive to markets changes [5].

\subsubsection{Global economy under the pandemic}

The five-factor model seems like a very effective tool to determine the invest underlying assets. Choosing the right pricing model is just the first step. Evaluating the environment is important as well especially during the pandemic

\subsubsection{Developing economies.}

COVID-19 has left the global market lots of negative impacts. Abiad et al. evaluate the impact of COVID-19 ON economy of developing Asian countries. By looking at the retails sales and sales and personal consumption expenditure during SARS (another severe epidemic happening between 2002-2003 mostly in Asian countries), the global economy, especially developing economies are very likely to encounter sharp decline and both supply and demand side would be greatly affected [6].

\subsubsection{The world overall}

As for developing economies, the entire world is greatly impacted. Nicola et al. research the impacts resulted from COVID-19 at different sectors, which includes primary, secondary and tertiary industries to determine what kind of socio-economic implications can be learned from the pandemic. By reporting economic losses of different industries and individuals working at different industries as well as surveying people's attitudes towards the pandemic, some new socioeconomic development plan is necessary and need to be implemented sector by sector. The reason is that the pandemic severely impacted the global economy in a negative manner. Hence, measures by government and financial institutions are in urgent needs [7].

\subsubsection{Recovery from the pandemic.}

The sad news is that it is extremely hard for economies to recover by themselves. Sarkodie and Owusu assess the global impact caused by COVID-19 from environmental, health and economic perspectives [8]. By comparing the effectiveness of different economic stimulus and fiscal policy packages offered by the governments of different countries, government intervention is required in order to reinvigorate the economy after the pandemic [8]. Government intervention would be helpful in terms of recapturing and maintaining economic productivity. 


\subsection{Objective}

As discussed above, in order to minimize the economic loss during and after the pandemic, choosing the right portfolio to invest and figure out how the pandemic is correlated with portfolio performance become more critical than ever. The market is experiencing some drastic changes since the pandemic. In 2020, the U.S stock market fused four times within 10 days during the first quarter of 2020 , which is also the time that COVID-19 outbreaks in the U.S [9]. The feasibility of Fama-French five-factor model is applied in many studies and applications. Therefore, in order to help the investors to make the reasonable decision, the next crucial step is using the model to examine and analyse different available portfolios.

\section{METHOD}

\subsection{Development and shortcomings of three- factor model}

In 1964, the single factor model, which only consists the factor "beta" was developed and was known as the capital assets pricing model. By using beta, how much each stock moved in relation to the entire stock market can be measured [10]. Higher beta indicates higher risk as well as higher returns and vice versa. By combining beta to two new factors, which are small company stocks and value stock, Fama and French introduced their three-factor asset pricing model, which delivers a more precise and reasonable performance in terms of explaining and predicting stock returns when compared to the single factor model. The three-factor model is designed as the tool that can measure the correlation between average return and size factor, and the relation between average return and price ratios like B/M. In the 1993 paper by Fama and French, there were the two outstanding improvements which were left unexplained by the CAPM of Sharpe [11] and Lintner [12].

\subsection{Development of five-factor model}

However, even being improved a lot, the three-factor model still failed to explain some anomalies and the cross-sectional variation associated with profitability and investment. The equation of the three-factor model is shown as [13]:

$$
\mathrm{R}_{\mathrm{it}}-\mathrm{R}_{\mathrm{Ft}}=\mathrm{a}_{\mathrm{i}}+\mathrm{b}_{\mathrm{i}}\left(\mathrm{R}_{\mathrm{Mt}}-\mathrm{R}_{\mathrm{Ft}}\right)+\mathrm{s}_{\mathrm{i}} \mathrm{SMB}_{\mathrm{t}}+\mathrm{h}_{\mathrm{i}} \mathrm{HML}_{\mathrm{t}}+\mathrm{e}_{\mathrm{it}} \cdot \text { (1) }
$$

By using the dividend discount model as the theoretical starting point, Fama and French developed the five-factor model with the time series regression equation shown as below [13]:

$$
\begin{aligned}
R_{i t}-R_{F t}= & a_{i}+b_{i}\left(R_{M t}-R_{F t}\right)+s_{i} S M B_{t}+h_{i} H M L_{t}+t+ \\
& r_{i} R M W_{t}+c_{i} C M A_{t}+e_{i t} .
\end{aligned}
$$

In Eq (2), $\mathrm{R}_{\mathrm{it}}$ refers to the returns on portfolios in which $i$ stands for the portfolio and $t$ stands for the time period. $R_{F t}$ is the risk-free return. $R_{M t}$ is the return on portfolios which has to be value weighted. Their difference is the excess return on market portfolio. $S M B_{t}$ refers to the difference on the return of a diversified portfolio of a small stock minus the return of a diversified portfolio of a big stock. $H M L_{t}$ stands for the difference of returns on diversified portfolios with high or low $\mathrm{B} / \mathrm{M}$, which means the book-to market ratio. $e_{i t}$ is the zero-mean residual. All the coefficients, $b_{i}, s_{i}, h_{i}, r_{i}$ and $c_{i}$, apprehends the variation in expected returns. The intercept, $a_{i}$, remains zero for all portfolios and securities. The other two variables, $R M W_{\mathrm{t}}$ and $C M A_{\mathrm{t}}$, are the key that makes the five-factor model distinctive from the three-factor model. $C M A_{\mathrm{t}}$ measures the difference of returns between diversified portfolios of stocks from high investment firm, which holds a more aggressive attitudes towards the investment and low investment firms with a more conservative attitude. Another variable that indicates some difference between types of portfolios is $R M W_{t}$, which refers to the difference between returns of diversified portfolios of stocks with robust or weak profitability. Given that the three-factor model is inadequate in terms of explaining anomalies and cross-sectional variation in expected returns, especially when it comes to investment and profitability, the addition of two new variables, which are $C M A_{t}$ and $R M W_{t}$, greatly enhances the performance of Fama-French model in explaining variation that could happen to be expected returns [13].

\section{RESULTS}

\subsection{Data collection}

The data of this study is obtained from the data library of Dartmouth College [14]. Based on the timeline of the pandemic, the data has been segmented into two time periods. The first period is from June 2019 to February 2020, which is before the outbreak of the pandemic. This time period is defined as the "before" of COVID-19. The other period ranges from March 2020 to November 2020, during which the economy is experiencing the impacts from COVID-19. In order to hold other factors constant to ensure the feasibility of the study, these two time periods are with the same length, consisting of eight months equally. The mathematical approach applied in this study is multiple regression analysis, which is often used to predict the outcome or performance of a respondent variable by using more than one explanatory variables. In this study, the respondent variable, in other words, the dependent variable, is the average value weighted returns on portfolios of 17 industries of the U.S. The independent variables, which are used as the explanatory variables in this study, are the 5 factors of the Fama-French model. In order to conduct more reasonable and accurate 
comparison and analysis, all data is up to date which is reported on a daily basis. By running multiple variable regression for different industries, the summaries of statistics of 17 industries are obtained, respectively (As shown in Table 1 and 2). Subsequently, the coefficient, the t-statistic and p-value of each are summarized to find out which industry experienced the most drastic impact resulted from the pandemic. The first step is comparing the t-statistic and p-value to determine if the statistical significance has changed or not before and during COVID-19. When the statistical significance is confirmed, the second step is comparing the coefficient to see if the plus/minus sign is changed, which means the correlation has been conversed. Industry with the most differences is identified as the industry that encountered most impacts. The statistical results indicate that all the industries have been altered by the pandemic at various extent and in different manners.

\subsection{Tables}

Table 1 Regression Summary Output for Car Industry (2019.6-2020.2, before the pandemic)

\begin{tabular}{|l|l|l|l|l|}
\hline & Coefficient & $\begin{array}{l}\text { Standard } \\
\text { Error }\end{array}$ & $\begin{array}{l}\text { t- } \\
\text { statistic }\end{array}$ & $\begin{array}{l}\text { P- } \\
\text { value }\end{array}$ \\
\hline Intercept & 0.0900 & 0.0724 & 1.2438 & 0.2152 \\
\hline $\boldsymbol{R}_{i t}-\boldsymbol{R}_{\boldsymbol{F} t}$ & 1.1405 & 0.0867 & 13.1543 & $\begin{array}{l}3.29 \mathrm{E}- \\
28\end{array}$ \\
\hline $\boldsymbol{S M B}_{t}$ & 0.1528 & 0.1626 & 0.9402 & 0.3483 \\
\hline $\boldsymbol{H M L}_{t}$ & 0.2787 & 0.1659 & 1.6802 & 0.0946 \\
\hline $\boldsymbol{R M W}_{\boldsymbol{t}}$ & -0.0046 & 0.2738 & -0.0167 & 0.9867 \\
\hline $\boldsymbol{C M A}_{t}$ & -0.2292 & 0.3164 & -1.7078 & 0.0894 \\
\hline
\end{tabular}

Table 2 Regression Summary Output for Car Industry (2020.3-2020.11, during the pandemic)

\begin{tabular}{|l|l|l|l|l|}
\hline & Coefficient & $\begin{array}{l}\text { Standard } \\
\text { Error }\end{array}$ & $\begin{array}{l}\text { t- } \\
\text { statistic }\end{array}$ & $\begin{array}{l}\text { P- } \\
\text { value }\end{array}$ \\
\hline Intercept & 0.2667 & 0.0841 & 3.1734 & 0.0018 \\
\hline $\boldsymbol{R}_{\boldsymbol{i t}}-\boldsymbol{R}_{\boldsymbol{t} t}$ & 0.9219 & 0.0372 & 24.7687 & $\begin{array}{l}1.2 \mathrm{E}- \\
60\end{array}$ \\
\hline $\boldsymbol{S M B}_{\boldsymbol{t}}$ & 0.8885 & 0.0989 & 9.9851 & $\begin{array}{l}2.98 \mathrm{E}- \\
16\end{array}$ \\
\hline $\boldsymbol{H M L}_{\boldsymbol{t}}$ & 0.2449 & 0.0806 & 3.0397 & 0.0027 \\
\hline $\boldsymbol{R M W}_{\boldsymbol{t}}$ & 0.5761 & 0.1702 & 3.3856 & 0.0009 \\
\hline $\boldsymbol{C M A}_{t}$ & -0.2292 & 0.2139 & -1.0715 & 0.2854 \\
\hline
\end{tabular}

Among all the industries being affected, the car industry displays most changes in variables compared to the other 16 industries. Given that the critical value at
$95 \%$ confidence interval, 4 out of 6 variables show a different statistical significance before and during COVID-19. The intercept, $S M B_{t}, H M L_{t}$, and $R M W_{t}$ are not statistically significant before pandemic and becomes significant during the pandemic. $R_{i t}-R_{F t}$ shows statistical significance before and during the pandemic. $C M A_{t}$ is not statistically significant before and is statistically significant during COVID-19. In addition, the coefficient of intercept indicates that the anomaly exists during the pandemic. COVID-19 also leads coefficient of $R_{i t}-R_{F t}$ to drop from 1.14 to 0.92 . The coefficients of $S M B_{t}, H M L_{t}$ and $C M A_{t}$ are positive. Due to the greatest distinction and most differences, car industry will be used as the objective for analysis through the remainder of this paper.

\section{DISCUSSION}

\subsection{Intercept}

The statistically significance of the intercept is different before and during the pandemic. Before the pandemic it is not statistically significant. However, during COVID-19, it becomes statistically significant. This change indicates the occurrence of anomalies within the market which brings risks that cannot be necessarily explained by another variable. The pandemic impacts the car industry from both supply and demand side. The liquidity problem faced with the suppliers of automotive-related industries and the reduction in demand of consumers resulted from the shutdown are believed to be potential long-term impact on the car industry [15]. It is very likely that the anomaly is resulted from the pandemic.

\section{2. $\boldsymbol{R}_{M t}-\boldsymbol{R}_{F t}$}

$R_{M t}-R_{F t}$ stands for the excess return on market portfolio. It remains statistically significant before and during the pandemic. Its coefficient decreases from 1.14 to 0.92 after the outbreak, which indicates the sensitivity of the car industry to market decreased. During the pandemic, layoffs occur throughout the entire industry [16]. One reason for firms to do so is controlling costs from the supply side since the demand side has been greatly hit by COVID-19. These kinds of cost-reducing actions tend to help firms from experiencing excessive market risk, i.e., the sensitivity is decreased.

\section{3. $S M B_{t}$}

$S M B_{t}$, which is the size factor, measures the difference in returns of small stocks minus big stocks, used to be not statistically significant and becomes significant during the pandemic. It has a positive value and reveals that returns of stock of small companies are higher than large companies. One possible explanation to this is that rate of return of small companies are 
usually higher because their volatility tends to be higher as well. Therefore, the investors need higher earning rate as compensations. For example, the implied volatility American multi-cinema, which is a small cap company, is 149.6 and is ranked $53 \%$ percentile. Amazon, the big cap company, its implied volatility is 24 and ranked in 0 percentile [17].

\subsection{HML}

$H M L_{t}$, which measures the differences of returns of high and low B/M firms' stocks, shows the differences between value stocks and growth stocks. It is not statistically significant before the pandemic while becomes significant and has a positive coefficient during the pandemic, which indicates that the companies with high $\mathrm{B} / \mathrm{M}$ ratios were favored by the investors. Given that companies with higher $\mathrm{B} / \mathrm{M}$ ratios can be considered as the value stocks, one possible reason to explain the higher returns is that the fundament of companies with a higher $\mathrm{B} / \mathrm{M}$ ratio tend to be more stable. On the other hand, in consideration of the inconstant economic condition during the pandemic, the drawdown tends to be greater than usual for growth stock companies, which would lead the investors to be more conservative investing in growth stock firms.

\subsection{RMW}

$R M W_{t}$ is the difference between portfolios with robust and weak profitability. It is the not statistically significant before and tends to be statistically significant during the pandemic. In addition, the coefficient of this variable becomes positive during the pandemic. This distinction indicates the fact that after the outbreak of the pandemic, the market is inclined to companies with continuous profitability. The pandemic has impacted the entire economy in a negative way and increases the uncertainty of the stock market. Therefore, it is understandable that investors now prefer investing companies that delivers relatively stable performance to control the risk and uncertainty as much as possible.

\subsection{HML}

$C M A_{t}$ is the difference of returns on stocks of conservative and aggressive investment firms. Before and during the pandemic, it is not statistically significant on car industry. Unlike technology or finance industry which are new and still under being developed, car industry is more mature. Therefore, compared to newly emerging industries, less changes and uncertainty are expected to occur within the car industry. No matter the investment tends to be more conservative or aggressive, for a mature industry, the impact is limited, which can explain why $C M A_{t}$ is not statistically significant before and during the pandemic.

\section{CONCLUSION}

In summary, Fama-French five-factor model is considered as superior when being compared to threefactor model because it can explain anomalies and the cross-sectional variation that occur in the stock market resulted from profitability and investment. The outbreak of COVID-19 has shrunk the economy as well as the stock market couple times. Therefore, while, being able to detect anomalies becomes more crucial when making investment decisions than ever during the pandemic. Based on the analysis of difference of coefficients and statistical significance detected on variables of the fivefactor model before and during the pandemic, the following conclusions are reached. The pandemic tends to leave the stock market anomalies, i.e., it is likely that the sensitivity of portfolios to market will be changed during the pandemic. In views of the higher volatility, investors need to be extra cautious while investing stocks of small companies although their return ratios are higher. The pandemic added uncertainty to the investment market. As a risk-averse investor, it is less risky to invest growth stock company and companies that are more likely to deliver constant performance. Compared to emerging industries, mature industries such as the car industry are less likely to be impacted by the pandemic overall. Thus, they tend to be better options for investment during the pandemic. These results offer a guideline for investors who still want to enter the market after it is impacted by the pandemic.

\section{REFERENCES}

[1] Chiah, M., Chai, D., \& Zhong, A. (2015). A Better Model? An Empirical Investigation of the FamaFrench Five-Factor Model in Australia. SSRN Electronic Journal, 1-44 https://doi.org/10.2139/ssrn.2557841

[2] Huang, T. L. (2019). Is the Fama and French fivefactor model robust in the Chinese stock market? Asia Pacific Management Review, 24(3), 278-289. https://doi.org/10.1016/j.apmrv.2018.10.002

[3] Lin, Q. (2017). Noisy prices and the Fama-French five-factor asset pricing model in China. Emerging Markets Review, 31, 141-163. https://doi.org/10.1016/j.ememar.2017.04.002

[4] Dirkx, P., \& Peter, F. (2018). Implementing the Fama-French Five-Factor Model for the German Stock Market. SSRN Electronic Journal, 1-22. https://doi.org/10.2139/ssrn.3300642

[5] Hou, D., \& Chen, Z. (2021). Research on the application of Fama-French 5-factor model in the steel industry during COVID-19. Journal of Physics: Conference Series, 1865(4), 042104. https://doi.org/10.1088/1742-6596/1865/4/042104 
[6] Abiad, A., Arao, M., Dagli, S., Ferrarini, B., Noy, I., Osewe, P., Pagaduan, J., Park, D., \& Platitas, R. (2020). The Economic Impact of the COVID-19 Outbreak on Developing Asia. ADB Briefs, 1-14. https://doi.org/10.22617/brf200096

[7] Nicola, M., Alsafi, Z., Sohrabi, C., Kerwan, A., AlJabir, A., Iosifidis, C., Agha, M., \& Agha, R. (2020). The socio-economic implications of the coronavirus pandemic (COVID-19): A review. International Journal of Surgery, 78, 185-193. https://doi.org/10.1016/j.ijsu.2020.04.018

[8] Sarkodie, S. A., \& Owusu, P. A. (2020). Global assessment of environment, health and economic impact of the novel coronavirus (COVID-19). Environment, Development and Sustainability, 23(4), 5005-5015. https://doi.org/10.1007/s10668$\underline{020-00801-2}$

[9] Zhang, J. (2020, March 18). Us stock market fuses again! 4 times in 10 days. GbizQ. https://www.gbizq.com/us-stock-market-fusesagain-4-times-in-10-days/

[10] Fama French Five Factor Asset Pricing Model. (2020, March 3). Quantitative Finance \& Algo Trading Blog by QuantInsti. https://blog.quantinsti.com/fama-french-fivefactor-asset-pricing-model/

[11] Sharpe, W. F. (1964, September 1). CAPITAL ASSET PRICES: A THEORY OF MARKET EQUILIBRIUM UNDER CONDITIONS OF RISK*. Wiley Online Library. https://onlinelibrary.wiley.com/doi/full/10.1111/j.1 540-6261.1964.tb02865.x
[12] Lintner, J. (1965). Security Prices, Risk, and Maximal Gains from Diversification. The Journal of Finance, 20(4), https://doi.org/10.2307/2977249

587.

[13] Fama, E. F. (2014, September 1). A Five-Factor Asset Pricing Model by Eugene F. Fama, Kenneth R. French: SSRN. Eugene F. Fama, Kenneth R. French.

https://papers.ssrn.com/sol3/papers.cfm?abstract_id $=2287202$

[14] Kenneth R. French - Description of Fama/French Factors. (n.d.). Dartmouth College. Retrieved July 1, 2021, from https://mba.tuck.dartmouth.edu/pages/faculty/ken.f rench/Data_Library/f-f_5_factors_2x3.html

[15] Accenture. (2020, April 23). From survival to revival for automotive suppliers post COVID-19. https://www.accenture.com/usen/insights/industrial/coronavirus-automotivesuppliers-recovery

[16] COVID-19 and the Automotive Industry: Changes, Challenges and the Future - Dartmouth Undergraduate Journal of Science. (2020b, November 9). Dartmouth Undergraduate Journal of Science. https://sites.dartmouth.edu/dujs/2020/11/09/covid19-and-the-automotive-industry-changeschallenges-and-the-future/

[17] Find Symbols Results for “null." (n.d.). MarketChameleon.Com. https://marketchameleon.com/Overview/ 